\title{
Efficacy and Safety of Daclatasvir and Sofosbuvir in Egyptian Patients with Chronic Hepatitis C Genotype 4 and Cirrhosis
}

\author{
AHMAD E. SHAMS EL-DIN, M.B.B.Ch.*; MAMDOUH A. GABR, M.D.*; AMR M. GAWALY, M.D.* and \\ MANAL A. EID, M.D.** \\ The Departments of Internal Medicine* and Clinical Pathology**, Faculty of Medicine, Tanta University
}

\begin{abstract}
Background: Hepatitis C virus (HCV) infection is a leading cause of Chronic Liver Disease (CLD) and liver transplantation globally. Currently, oral combinations of Direct Acting Antiviral agents (DAAs) are the standard of care for treating chronic HCV infection.
\end{abstract}

Aim of Study: To assess the efficacy \& safety of combination of Daclatasvir and Sofosbuvir in Egyptian patients with chronic hepatitis C Genotype 4 and Cirrhosis.

Patients and Methods: 50 Egyptian, cirrhotic patients with HCV genotype 4 infection were treated with a generic form of sofosbuvir (SOF) 400mg, daclatasvir (DCV) 60mg with or without weight-based ribavirin (RBV) for only 12 weeks. 40 out of the 50 patients enrolled in the study, completed treatment, while the remaining 10 patients were lost for follow-up.

Results: The 12 weeks combination of SOF plus DCV achieved SVR in all treated patients $(100 \%)$ whether treatmentnaïve or experienced, with or without ribavirin. A significant improvement was observed in transaminases, while a nonsignificant improvement was observed in serum albumin, bilirubin, INR and the mean CTP score indicating improvement in liver functions. Regarding safety outcomes, all treatmentrelated AEs were only minor AEs with no major AEs.

Conclusion: The combination of SOF plus DCV with or without RBV for only 12 weeks is highly effective in treating HCV GT4 cirrhotic patients with SVR 12 rate of $100 \%$, safe and well tolerated by these cirrhotic patients. Moreover, there was a marginal improvement in liver functions observed 12 weeks after treatment.

Key Words: H. C. V-Chronic liver disease (CLD) - Cirrhosis.

\section{Introduction}

HEPATITIS C Virus (HCV) infection is a leading cause of Chronic Liver Disease (CLD) and liver transplantation globally [1]. HCV genotype 4 is responsible for approximately $13 \%$ of the cases of

Correspondence to: Dr. Ahmad E. Shams El-Din,

The Department of Internal Medicine, Faculty of Medicine, Tanta University chronic HCV infection worldwide [2]. Egypt has the highest prevalence of $\mathrm{HCV}$ infection worldwide $(15 \%)$, and genotype 4 represents $90 \%$ of all these cases, while the remaining $10 \%$ are due to $\mathrm{HCV}$ genotype 1 [3].

Among patients with chronic hepatitis $\mathrm{C}$, those with cirrhosis have the greatest clinical challenge. These patients need effective antiviral therapy to prevent progression to decompensation, end stage liver disease and Hepatocellular Carcinoma (HCC) [4] . Currently, oral combinations of Direct Acting Antiviral agents (DAAs) are the standard of care for treating chronic $\mathrm{HCV}$ infection [5] .

Therefore, in this real-life cohort, the primary aim of the present study is to assess the efficacy and safety of combination of daclatasvir and sofosbuvir with or without ribavirin in the treatment of a group of Egyptian patients with chronic hepatitis $\mathrm{C}$ genotype 4 and cirrhosis.

\section{Patients and Methods}

In the period from April 2017 to April 2018 a total of 50 Egyptian, cirrhotic patients with HCV genotype 4 infection which were the subject of the present study were selected and identified from Tanta Liver Center and outpatient clinic of Internal Medicine Department Tanta University.

All the study group were subjected to the following:

1- Full history taking including risk factors of $\mathrm{HCV}$ infection.

2- Complete physical examination searching for stigmata of liver cirrhosis.

3- Laboratory studies including: Urine, $\mathrm{CBC}$, random blood sugar, prothrombin. (Activity and INR), liver biochemical tests including: Bilirubin, ALT, AST, serum albumin and viral 
markers: HCV Ab, HBS Ag, HCV RNA by RT PCR.

4- Abdominal US scan to assess liver status, splenic size and ascites.

5- Severity of liver cirrhosis was determined by estimation of Child-Turcotte Pugh (CTP) score depending on clinical, biochemical and US findings.

6- Treatment regimen: All the study group were assigned to receive an all oral fixed dose of sofosbuvir (400mg) plus daclatasvir (60mg) \pm weight-based ribavirin (1000 or $1200 \mathrm{mg}$ in patients $<75$ or $\geq 75 \mathrm{~kg}$, respectively) for only 12 weeks. The primary end point is Sustained Virological Response (SVR) at 12 weeks after the end of treatment (SVR12).

7- Follow-up laboratory studies were done 4 weeks, 12 weeks after initiation of therapy as well as 12 weeks after the end of treatment including HCV RNA by RT PCR.

8- Also, treatment-related adverse events as well as any complications observed during the study were recorded and dealt with accordingly.

9- The CTP score was estimated after SVR and any changes from the pretreatment level were also recorded.

Exclusion criteria: Patients with decompensated cirrhosis, HCV/HBV or HCV/HIV co-infection, $\mathrm{HCC}$ were not eligible for enrollment. Patients with any of the following laboratory abnormalities were also excluded from enrollment: Hemoglobin level less than $10 \mathrm{gm} / \mathrm{dl}$, platelets count of 30.000 $\mathrm{mm}^{3}$ or less, total bilirubin level greater than $10 \mathrm{mg} /$ $\mathrm{dl}$, serum creatinine level greater than $2.5 \mathrm{mg} / \mathrm{dl}$ and/or creatinine clearance $<40 \mathrm{ml} / \mathrm{min}$.

\section{Statistical analysis:}

One-way analysis of variance (ANOVA) was used to assess significant differences among treated group. The Tukey Test was used to show the significant effect of treatment. Values are expressed as mean $\pm \mathrm{SD}$. The criterion for statistical significance was set at $p<0.05$ (SPSS Inc., USA Software).

\section{Results}

As regard patient disposition by the studied group Fig. (1): 50 Egyptian, cirrhotic patients with HCV genotype 4 infection were the subject of the present study. 44 patients $(88 \%)$ were treatment naïve, while the remaining 6 patients $(12 \%)$ were treatment experienced. Out of 44 treatment naïve patients $34(77.3 \%)$ completed treatment and achieved SVR12 and 10 patients (22.7\%) were lost for follow-up. All treatment experienced patients $(n=6)$ completed treatment and achieved SVR12.

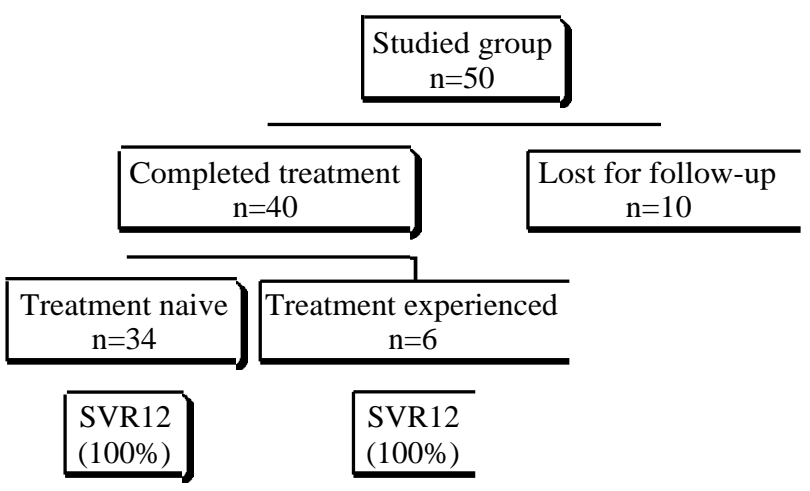

Fig. (1): Patient disposition by the studied group.

The clinical characteristics of the studied groups as regard demographic data, clinical examination, US findings, initial laboratory findings, viral markers \& level of viremia are shown in (Tables 1-5).

Table (1): Demographic data of the studied group $(n=50)$.

\begin{tabular}{llll}
\hline Item & & No. & $\%$ \\
\hline - Age: & Range & $35-77 \mathrm{y}$ & \\
& Mean \pm SD & $56 \pm 9.63 \mathrm{y}$ & \\
- Sex: & Male & 37 & 74 \\
& Female & 13 & 26 \\
- Residence: & Rural & 44 & 88 \\
& Urban & 6 & 12 \\
- Riskfactors & Dental procedures & 24 & 48 \\
of HCV infection $:$ & Surgery & 17 & 34 \\
& Family history & 14 & 28 \\
& IVantibilharzial ttt & 5 & 10 \\
- Comorbidity: & Blood transfusion & 4 & 8 \\
& DM & 8 & 16 \\
& COPD & 4 & 8 \\
- Previous & Thyroid disease & 1 & 2 \\
treatment: & Treatment naïve & 44 & 88 \\
\hline
\end{tabular}

Table (2): Results of clinical examination of the studied group $(\mathrm{n}=50)$.

\begin{tabular}{lll}
\hline Item & No. & $\%$ \\
\hline Edema of lower limb & 11 & 22 \\
Palmar erythema & 11 & 22 \\
Jaundice & 3 & 6 \\
Liver status: & & \\
Not palpable & 47 & 94 \\
Enlarged & 3 & 6 \\
Spleen: & & \\
Enlarged & 28 & 56 \\
Normal & 21 & 42 \\
Splenectomy & 1 & 2 \\
Ascites & - & 0 \\
&
\end{tabular}


Table (3): US findings in the studied group $(n=50)$.

Table (4): Initial lab findings in the studied group $(n=50)$.

\begin{tabular}{|c|c|c|c|c|c|c|}
\hline Item & No. & $\%$ & Lab findings & Range & \multicolumn{2}{|l|}{ Mean \pm SD } \\
\hline Liver status: & & & \multicolumn{4}{|l|}{$C B C:$} \\
\hline - Size. & & & \multirow{2}{*}{$\begin{array}{l}\mathrm{Hb} \% \\
\text { Platelets }\end{array}$} & $10-16.3$ & \multicolumn{2}{|l|}{$13.35 \pm 1.43$} \\
\hline - Size. & & & & \multirow{2}{*}{$2100-13.500$} & \multirow{2}{*}{\multicolumn{2}{|c|}{$\begin{array}{l}146140 \pm 78382.63 \\
5995.4 \pm 2412.39\end{array}$}} \\
\hline Normal & 36 & 72 & WBC & & & \\
\hline \multirow{2}{*}{ Enlarged } & & & \multirow{2}{*}{$\begin{array}{l}\text { Random blood sugar } \\
\text { S. Bilirubin }\end{array}$} & $71-332$ & \multicolumn{2}{|l|}{$127 \pm 54.94$} \\
\hline & 9 & 18 & & $0.3-3.8$ & \multicolumn{2}{|l|}{$1.2 \pm 0.84$} \\
\hline Shrunken & \multirow[t]{2}{*}{5} & 10 & ALT & $8-286$ & \multicolumn{2}{|l|}{$59.8 \pm 49.66$} \\
\hline \multicolumn{2}{|l|}{ - Echopattern: } & & AST & $8-331$ & \multicolumn{2}{|l|}{$66.1 \pm 55.37$} \\
\hline \multirow{2}{*}{ Cirrhotic } & \multirow{2}{*}{37} & \multirow{2}{*}{74} & S. Albumin & $2.6-5$ & \multicolumn{2}{|l|}{$3.9 \pm 0.61$} \\
\hline & & & Prothrombin: & & & \\
\hline Bright & 7 & 14 & Activity & $43-100 \%$ & $80 \% \pm 14.85$ & \\
\hline PPF & 6 & 12 & INR & $1-2.4$ & $1.3 \pm 0.27$ & \\
\hline & & & & nitial CTP score & & \\
\hline - Hepatic focal lesion & - & 0 & CTP sco & No. & $\%$ & \\
\hline - Portal vein: & & & Class A & 40 & 80 & \\
\hline Dilated & 26 & 52 & Class B & 10 & 20 & \\
\hline & & & Class C & - & 0 & \\
\hline Normal & 24 & 48 & Mean \pm & $6 \pm$ & & \\
\hline Splenic size: & & & & & & \\
\hline Enlarged & 31 & 62 & Table (5): Viral mar & ers \& level of vi & mia in the $s$ & died \\
\hline Normal & 18 & 36 & group $(\mathrm{n}$ & & & \\
\hline Splenectomy & 1 & 2 & Item & & No. & $\%$ \\
\hline Ascites & - & 0 & $\mathrm{HCV} \mathrm{Ab}$ & $+\mathrm{Ve}$ & 50 & 100 \\
\hline & & & HCV RNA & $+\mathrm{Ve}$ & 50 & 00 \\
\hline Others: & & & Range & $673-13,234$ & & \\
\hline & & & Mean & $1,579,174$ & & \\
\hline Gall stones & 1 & 2 & High viral load $(\geq 600$ & 000) & 24 & 48 \\
\hline
\end{tabular}

Table (6): Review of laboratory findings in the treated group $(n=40)$.

\begin{tabular}{|c|c|c|c|c|c|c|c|}
\hline \multirow[t]{2}{*}{ Item } & \multirow{2}{*}{$\begin{array}{l}\text { Pre-treatment } \\
\text { Mean } \pm \text { SD }\end{array}$} & \multicolumn{2}{|c|}{$\begin{array}{c}4 \mathrm{~W} \text { on treatment } \\
\text { (RVR) }\end{array}$} & \multicolumn{2}{|c|}{$\begin{array}{l}\text { End of treatment (12W) } \\
\text { (ETR) }\end{array}$} & \multicolumn{2}{|c|}{$\begin{array}{l}12 \mathrm{~W} \text { after end of treatment } \\
\text { (SVR) }\end{array}$} \\
\hline & & Mean \pm SD & $p$-value & Mean \pm SD & $p$-value & Mean \pm SD & $p$-value \\
\hline Hemoglobin & $13.31 \pm 1.5$ & $12.11 \pm 1.3$ & $<0.01$ & $12.05 \pm 1.7$ & $<0.01$ & $12.76 \pm 2$ & $>0.05$ \\
\hline Platelets count & $157525 \pm 80589$ & $170100 \pm 82746$ & $>0.10$ & $171625 \pm 83804$ & $>0.10$ & $167375 \pm 81870$ & $>0.10$ \\
\hline Bilirubin & $1.1 \pm 0.66$ & $1.06 \pm 0.46$ & 0.08 & $1 \pm 0.58$ & 0.09 & $0.79 \pm 0.51$ & $>0.10$ \\
\hline ALT & $63.03 \pm 50.11$ & $27.73 \pm 15.09$ & $<0.001$ & $22.35 \pm 10.14$ & $<0.001$ & $16.4 \pm 5.99$ & $<0.001 *$ \\
\hline AST & $69.15 \pm 58.99$ & $34.33 \pm 17.26$ & $<0.001$ & $29.25 \pm 17.63$ & $<0.001$ & $21.03 \pm 10.93$ & $<0.001 *$ \\
\hline S. albumin & $3.98 \pm 0.65$ & $3.89 \pm 0.55$ & 0.0177 & $3.95 \pm 0.57$ & $>0.10$ & $4.11 \pm 0.6$ & $>0.10$ \\
\hline INR & $1.26 \pm 0.23$ & $1.12 \pm 0.18$ & 0.241 & $1.02 \pm 0.03$ & 0.262 & $1.05 \pm 0.08$ & 0.234 \\
\hline HCV RNA & $1457586 \pm 186453$ & $46755.83 \pm 16666$ & $<0.001$ & 0 & $<0.001$ & 0 & $<0.001 *$ \\
\hline
\end{tabular}

*: Significant $p$-value $<0.05$.

Table (7): Primary outcome of treatment with sofosbuvir plus daclatasvir \pm ribavirin in the treated group $(\mathrm{SVR} 12)(\mathrm{n}=40)$.

\begin{tabular}{|c|c|c|c|c|c|c|c|c|}
\hline \multirow[t]{2}{*}{ Variable } & \multicolumn{2}{|c|}{$\begin{array}{l}\text { Complete } \\
\text { RVR }\end{array}$} & \multicolumn{2}{|c|}{$\begin{array}{l}\text { Incomplete } \\
\text { RVR }\end{array}$} & \multicolumn{2}{|c|}{ ETR } & \multicolumn{2}{|c|}{ SVR12 } \\
\hline & No. & $\%$ & No. & $\%$ & No. & $\%$ & No. & $\%$ \\
\hline Treatment-naïve $(n=34)$ & 31 & 91.1 & 3 & 8.9 & 34 & 100 & 34 & 100 \\
\hline Treatment-experienced $(n=6)$ & 6 & 100 & - & 0 & 6 & 100 & 6 & 100 \\
\hline
\end{tabular}


Table (8): Treatment-related adverse events in the treated group $(n=40)$.

\begin{tabular}{lll}
\hline Item & No. & $\%$ \\
\hline Minor adverse events: & & \\
Anaemia & 21 & 52.5 \\
Headache & 4 & 10 \\
Fatigue & 4 & 10 \\
Dry cough & 3 & 7.5 \\
Itching & 1 & 2.5 \\
Insomnia & - & 0 \\
Major adverse events: & & \\
Death & - & 0 \\
Liver cell failure & - & 0 \\
Hepatic encephalopathy & & 0 \\
Development of HCC & 1 & 2.5 \\
\hline
\end{tabular}

No major adverse event (death, liver cell failure or hepatic encephalopathy) was reported in any patient of the treated group $(0 \%)$. However, one of our patient $(2.5 \%)$ developed HCC 3 months after achieving a SVR.

\section{Discussion}

In this real-life cohort, the primary aim of the present study is to assess the efficacy and safety of combination of daclatasvir and sofosbuvir with or without ribavirin in the treatment of a group of Egyptian patients with chronic hepatitis $\mathrm{C}$ genotype 4 and cirrhosis. This population, which is often under-represented in clinical trials, is less likely to respond satisfactorily to treatment and also may experience more treatment-related adverse events.

Our results revealed, a non-significant improvement in serum albumin, bilirubin and INR, while a highly significant improvement was observed in the level of transaminases 12 weeks after the end of treatment with SOF, DCV \pm RBV (Table 6). A finding that indicates the safety of this treatment modality regarding the synthetic functions of the liver. Moreover, the highly significant decrease in the level of transaminases 12 weeks after the end of treatment indicates marked improvement in the necroinflammatory process in the treated $\mathrm{CHCV}$ patients. Review of relevant publications, similar results were reported by 3 other national studies (Abdel-Moneim et al., [6], Ahmed et al., [7] and Abdel-Aziz et al., [8]) and 2 other international studies (Babatin et al., [9] \& Welzel TM, et al. [5]).

Similarly, the current treatment with SOF, DCV $\pm \mathrm{RBV}$ revealed non-significant changes in both hemoglobin and platelets count as compared to the baseline values. A finding that could be considered another advantage of this regimen besides its efficacy, especially in this group of cirrhotic patients in whom cytopenia is a common finding. Needless to say, the non-significant decrease in hemoglobin level observed 12 weeks after the end of treatment could be related to the use of ribavirin, however being non-significant, none of our treated patients required transfusion and/or discontinuation of RBV. Consequently, most of these cases were managed by reducing the RBV dose and in some cases addition of epoetin (EPO). It is noteworthy to mention that, concerning efficacy and antiviral response, the 12 weeks combination of SOF plus DCV achieved SVR in all treated patients (100\%) whether treatment naïve or experienced, with or without ribavirin (Table 7). There was only one patient who didn't receive ribavirin due to anaemia achieving the same response for only 12 weeks (SVR12).

Review of relevant publications revealed, some discrepancies between the results of the present study and the other national and international studies. In keeping with our results, 2 other studies (Babatin et al., [9] \& Fontaine et al., [10]) achieved SVR12 in $100 \%$ of their treated GT4 cirrhotic patients. On further subanalysis, the presence of detectable HCV RNA at week 4 in some patients in this study (8\%) was not associated with virologic relapse, almost the same results observed in our study $(8.9 \%)$. By contrast, 5 other national studies reported a relatively lower SVR12 rate in cirrhotic GT4 patients treated with this combination (SOF, DCV \pm RBV), such as Abdel-Aziz et al., (91\%) [8], El-Khayat et al. (94\%) [11], Abdel-Moneim et al., (94\%) [6], Omar et al., (95\%) [12] \& Ahmed et al., (96\%) [7]. Regarding safety outcomes, all treatment-related AEs reported in our treated group were minor adverse events including, anaemia in $21(52.5 \%)$, headache in $4(10 \%)$, fatigue in 4 $(10 \%)$, dry cough in $3(7.5 \%)$ and itching in only one patient $(2.5 \%)$ (Table 8). Interestingly, none of our patients $(0 \%)$ developed serious AEs such as (death, liver cell failure or hepatic encephalopathy). A finding that confirms the safety and tolerability of this regimen in our treated cirrhotic HCV GT4 patients. On further follow-up beyond the study period, one $(2.5 \%)$ of our cohort with $\mathrm{HCV}$ GT4 cirrhotic patients developed HCC 3 months after achieving a SVR. A finding that clearly shows that in cirrhotic CHCV patients, HCC can develop despite achieving a SVR. Therefore, continous surveillance for HCC should be done in cirrhotics even after achieving a SVR.

\section{Conclusion:}

The results of the present study clearly shows that, in cirrhotic GT4 Egyptian patients, the combination of SOF plus DCV with or without RBV 
for only 12 weeks is highly effective with SVR12 rate of $100 \%$. Also, it was equally effective in both naïve as well as treatment-experienced patients.

Additionally, this combination is safe and well tolerated by these cirrhotic patients. Moreover, there was a marginal improvement in liver functions observed 12 weeks after the end of therapy. Therefore, based on the results of this real-world study, this combination is not only highly effective and safe, but also the cheapest combination among currently available regimens in Egypt and this makes it a very suitable regimen for a developing country like ours and this will help make the end of $\mathrm{HCV}$ in the nearby future in Egypt a reality.

\section{Recommendations:}

Since the combination of SOF plus DCV with or without RBV for only 12 weeks is cheap, highly effective \& safe, in cirrhotic GT4 patients, it should be among the first line options for treatment of this group of patients in our country. The safety and tolerability of this regimen in cirrhotic GT4 patients recommends a further study for it's use in the treatment of decompensated GT4 cirrhosis. The development of HCC in one $(2.5 \%)$ of our patients 3 months after achieving a SVR warrants continous surveillance for HCC in cirrhotic patients even after achieving a SVR.

\section{Acknowledgements:}

We would like to thank all participants who helped during this study.

Conflict of interest: None declared.

\section{References}

1- POORDAD F., HEZODE C., TRINH R., KOWDLEY K.V., ZEUZEM S., et al.: ABT-450/r-ombitasvir and dasabuvir with ribavirin for hepatitis $\mathrm{C}$ with cirrhosis. New Eng. J. Med., 370 (21): 1973-82, 2014.

2- HATHORN E. and ELSHARKAWY A.M.: Management of hepatitis $\mathrm{C}$ genotype 4 in the directly acting antivirals era. B.M.J. Open Gastroenterology, 3 (1): p.e000112, 2016.

3- EL-AKEL W., EL-SAYED M.H., EL-KASSAS M., ELSERAFY M., KHAIRY M., et al.: National treatment programme of hepatitis C in Egypt: Hepatitis C virus model of care. J. Viral Hepatitis, 24 (4): 262-7, 2017.

4- REDDY K.R., BOURLIERE M., SULKOWSKI M., OMATA M., ZEUZEM S., et al.: Ledipasvir and sofosbuvir in patients with genotype 1 hepatitis $C$ virus infection and compensated cirrhosis: An integrated safety and efficacy analysis. Hepatol., 62 (1): 79-86, 2015.

5- BERTINO G., ARDIRI A., PROITI M., RIGANO G., FRAZZETTO E., et al.: Chronic hepatitis C: This and the new era of treatment. World J. Hepatol., 8 (2): 92, 2016.

6- ABDEL-MONEIM A., ABOUD A., ABDEL-GABAAR M., ZANATY M.I. and RAMADAN M.: Efficacy and safety of sofosbuvir plus daclatasvir with or without ribavirin: Large real-life results of patients with chronic hepatitis C genotype 4. Hepatol. International., 12 (4): 348-55, 2018

7- AHMED O.A., SAFWAT E., KHALIFA M.O., ELSHAFIE A.I., FOUAD M.H.A., et al.: Sofosbuvir plus daclatasvir in treatment of chronic hepatitis $\mathrm{C}$ genotype 4 infection in a cohort of Egyptian patients: An experiment the size of Egyptian village. International J. Hepatol., 2018.

8- ABDEL-AZIZ A.M., IBRAHIM M.A., EL-SHEIKH A.A., KAMEL M.Y., ZENHOM N.M., et al.: Effect of Sofosbuvir plus daclatasvir in hepatitis $\mathrm{C}$ virus genotype-4 patients: Promising effect on liver fibrosis. J. Clin. Exper. Hepatol., 8 (1): 15-22, ,2018.

9- BABATIN M.A., ALGHAMDI A.S., ALBENMOUSA A., ALASEERI A., ALJARODI M., et al.: Efficacy and safety of simeprevir or daclatasvir in combination with sofosbuvir for the treatment of hepatitis C genotype 4 infection. J. Clin. Gastroenterology, 52 (5): 452-7, 2018.

10- FONTAINE H., HEZODE C., ZOULIM F., SAMUEL D., BOURLIERE M., et al.: "Efficacy of the oral sofosbuvir-based combinations in HCV genotype 4monoinfected patients from the French observational cohort ANRS CO22 Hepather," in Proceedings of the 50 th Annual Meeting of European Association for the Study of the Liver,Vienna, Austria, 2015.

11- EL-KHAYAT H., FOUAD Y., MOHAMED H.I., ELAMIN H., KAMAL E.M., MAHER M. and RISK A.: Sofosbuvir plus daclatasvir with or without ribavirin in 551 patients with hepatitis C-related cirrhosis, genotype 4. Alimentary Pharmaco. \& Therap., 47 (5): 674-9, 2018.

12- OMAR H., EL-AKEL W., ELBAZ T., EL-KASSAS M. ELSAEED K., et al.: Generic daclatasvir plus sofosbuvir, with or without ribavirin, in treatment of chronic hepatitis C: Real-World results from 18378 patients in Egypt. Alimentary Pharmaco. \& Therap., 47 (3): 421-31, 2018. 


\section{تقييم فعالية وسلامة الدكلاتاسفيروالسوفوسبفير الونير

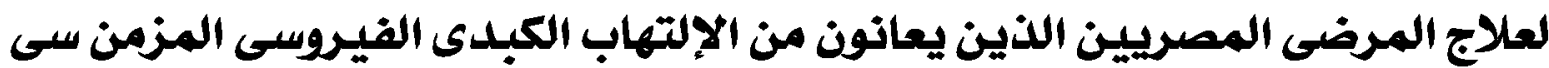

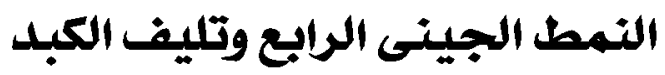

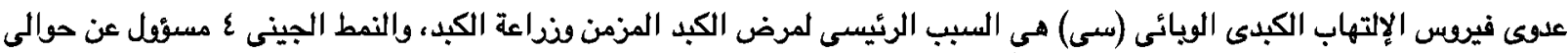

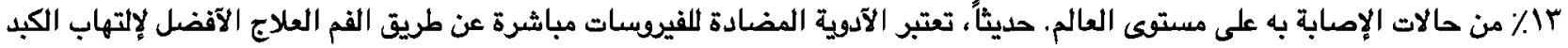

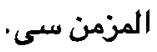

الهدف من البحث: تقييم فعالية وسلامة الدكلاتاسفير والسوفوسبفير لعلاج المرضى المصريين الذين يعانون من الإلتهاب الكبدى الفيرسىى المزمن سى النمط الجينى الرابع وتليف الكبد.

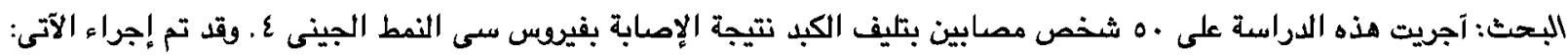

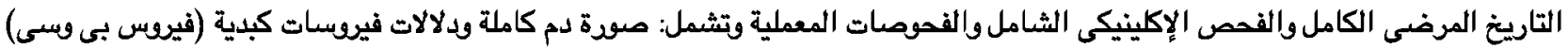

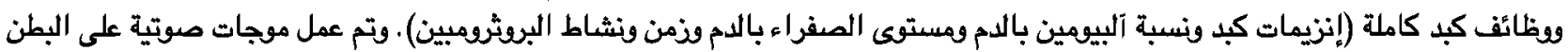

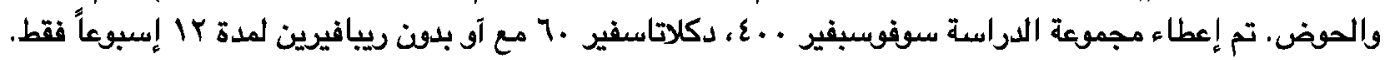

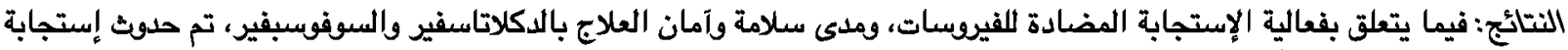

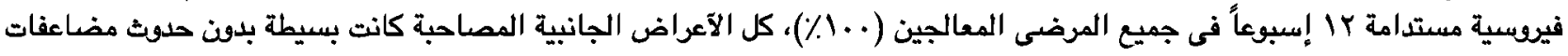
خطيرة.

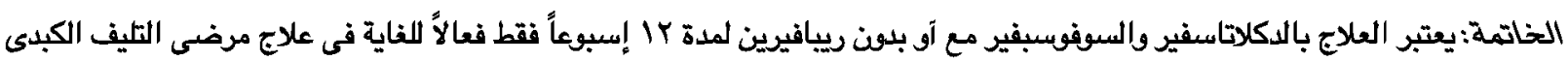

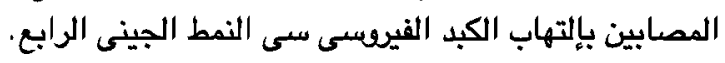

